\title{
Optimization of CNC end milling process parameters using PCA-based Taguchi method
}

\author{
${ }^{1}$ Sanjit Moshat, ${ }^{2 *}$ Saurav Datta, ${ }^{3}$ Asish Bandyopadhyay and ${ }^{4}$ Pradip Kumar Pal \\ ${ }^{1,3,4}$ Department of Mechanical Engineering, Jadavpur University, Kolkata- 700032, West Bengal, INDIA \\ ${ }^{2}$ Department of Mechanical Engineering, National Institute of Technology (NIT), Rourkela, Orissa-769008, INDIA \\ "Corresponding Author (e-mail: sdattaju@gmail.com, Saurav Datta)
}

\begin{abstract}
In order to build up a bridge between quality and productivity, the present study highlights optimization of CNC end milling process parameters to provide good surface finish as well as high material removal rate (MRR). The surface finish and material removal rate have been identified as quality attributes and are assumed to be directly related to productivity. An attempt has been made to optimize aforesaid quality attributes in a manner that these multi-criterions could be fulfilled simultaneously up to the expected level. This invites a multi-objective optimization problem which has been solved by PCA based Taguchi method. To meet the basic assumption of Taguchi method; in the present work, individual response correlations have been eliminated first by means of Principal Component Analysis (PCA). Correlated responses have been transformed into uncorrelated or independent quality indices called principal components. The principal component, imposing highest accountability proportion, has been treated as single objective function for optimization (multi-response performance index). Finally Taguchi method has been adapted to solve this optimization problem. The aforesaid methodology has been found fruitful in the cases where simultaneous optimization of huge number of responses is required.
\end{abstract}

Keywords: CNC end milling, surface finish, material removal rate (MRR), principal component analysis (PCA), Taguchi method

\section{Introduction}

In the proposed research work, material removal rate (MRR) and surface roughness of the product prepared by CNC end milling operation are to be studied experimentally and the results, thereof, obtained are to be interpreted analytically.

Quality and productivity are two important but conflicting criteria in any machining operations. In order to ensure high productivity, extent of quality is to be compromised. It is, therefore, essential to optimize quality and productivity simultaneously. Productivity can be interpreted in terms of material removal rate in the machining operation and quality represents satisfactory yield in terms of product characteristics as desired by the customers. Dimensional accuracy, form stability, surface smoothness, fulfillment of functional requirements in prescribed area of application etc. are important quality attributes of the product. Increase in productivity results in reduction in machining time which may result in quality loss. On the contrary, an improvement in quality results in increasing machining time thereby, reducing productivity.

The interdependence and correlation among quality and productivity is very complex and difficult to understand. It also depends on the tool-work material. Investigations on development of mathematical relationship and correlation that exists among aforesaid features have been attempted by previous researchers but to a limited extent. Literature depicts that optimization of MRR, product quality etc. has also been attempted. In most of the cases, optimization was based on single objective function. In practical case, it is felt that optimizing a single response may yield positively in some aspects but it may affect adversely in other aspects. The problem can be overcome if multiple objectives are optimized simultaneously. It is, therefore, required to maximize MRR, and improve product quality simultaneously by selecting an appropriate (optimal) process environment.

Milling is a versatile and useful machining operation. End milling is the most important milling operation and it is widely used in most of the manufacturing industries due to its capability of producing complex geometric surfaces with reasonable accuracy and 
surface finish. However, with the inventions of CNC milling machine, the flexibility has been adopted along with versatility in end milling process. It is found that many research works have been done so far on continuous improvement of the performance of end milling process.

In end milling, surface finish and material removal rate are two important aspects, which require attention both from industry personnel as well as in Research \& Development, because these two factors greatly influence machining performances. In modern industry, one of the trends is to manufacture low cost, high quality products in short time. Automated and flexible manufacturing systems are employed for that purpose. CNC machines are considered most suitable in flexible manufacturing system. Above all, $\mathrm{CNC}$ milling machine is very useful for both its flexibility and versatility. These machines are capable of achieving reasonable accuracy and surface finish. Processing time is also very low as compared to some of the conventional machining process.

On the other hand, material removal rate (MRR), which indicates processing time of the work piece, is another important factor that greatly influences production rate and cost. So, there is a need for a tool that should allow the evaluation of the surface roughness and material removal rate value before the machining of the part and which, at the same time, can easily be used in the production-floor environment contributing to the minimization of required time and cost and the production of desired surface quality.

Both the surface roughness and material removal rate greatly vary with the change of cutting process parameters. That is why proper selection of process parameters is also essential along with the prediction of the surface finish (lower $\mathrm{R}_{\mathrm{a}}$ value) and material removal rate in $\mathrm{CNC}$ end milling process.

Yang and Chen (2001) demonstrated a systematic procedure of using Taguchi parameter design in process control of individual milling machines. The Taguchi parameter design had been done in order to identify the optimum surface roughness performance with a particular combination of cutting parameters in an end-milling operation. Ghani et al. (2004) applied Taguchi optimization methodology to optimize cutting parameters in end milling while machining hardened steel with TiN coated carbide insert tool under semi-finishing and finishing conditions of high speed cutting considering the milling parameters - cutting speed, feed rate and depth of cut. Oktem et al. (2005) had focused on the development of an effective methodology to determine the optimum cutting conditions leading to minimum surface roughness in milling of mold surfaces by coupling Response Surface Methodology (RSM) with a developed genetic algorithm (GA).

Kopac and Krajnik (2007) presented the robust design of flank milling parameters dealing with the optimization of the cutting forces, milled surface roughness and the material removal rate (MRR) in the machining of an Al-alloy casting plate for injection moulds. Grey-Taguchi method combined the orthogonal array (OA) design of experiments (DOE) with grey-relational analysis (GRA), which enabled the determination of the optimal combination of milling parameters for multiple process responses.

Previous researchers have studied various aspects of process optimization of milling. It has been found that in most of the cases, Taguchi method along with grey relation analysis or RSM has been largely recommended. However, these approaches are based on the assumption that individual quality attributes are uncorrelated i.e. they have been treated as independent. But in practical case the reverse situation may arise.

In order to overcome this shortcoming, the present study proposes application of Principal Component analysis (PCA) coupled with Taguchi method to solve such correlated multi-attribute optimization of CNC end milling operation. PCA has been proposed to eliminate correlation between the responses and to estimate uncorrelated quality indices called principal components; Datta et al. (2009a). The quality index (principal component) having highest accountability proportion has been treated as equivalent single objective function; which has been finally optimized by Taguchi method.

\section{Principal Component Analysis (PCA)}

Principal Component Analysis (PCA) is a way of identifying patterns in the correlated data, and expressing the data in such a way so as to highlight their similarities and differences, Johnson and Wichern (2002). The main advantage of PCA is that once the patterns in data have been identified, the data can be compressed, i.e. by reducing the number of dimensions, without much loss of information. The methods involved in PCA are discussed below:

1. Getting some data

2. Normalization of data

3. Calculation of covariance matrix.

4. Interpretation of covariance matrix.

The normalized data have then been utilized to construct a variance-covariance matrix $M$, which is illustrated as below: 


$$
\begin{gathered}
M=\left[\begin{array}{cccccc}
N_{1,1} & N_{1,2} & \cdot & \cdot & \cdot & N_{1, u} \\
N_{2,1} & N_{2,2} & \cdot & \cdot & \cdot & N_{2, p} \\
\cdot & \cdot & \cdot & \cdot & \cdot & \cdot \\
\cdot & \cdot & \cdot & \cdot & \cdot & \cdot \\
N_{q, 1} & N_{q, 2} & \cdot & \cdot & \cdot & N_{q, p}
\end{array}\right] \\
\text { where } N_{k, l}=\frac{\operatorname{Cov}\left(Y_{i, k}^{*}, Y_{i, l}^{*}\right)}{\sqrt{\operatorname{Var}\left(Y_{i, k}^{*}\right) \operatorname{Var}\left(Y_{i, l}^{*}\right)}}
\end{gathered}
$$

In which $u$ stands for the number of quality characteristics and $p$ stands for the number of experimental runs. Then, eigenvectors and Eigenvalues of matrix $M$ can be computed, which are denoted by $\bar{V}_{j}$ and $\lambda_{j}$ respectively.

In PCA the eigenvector $\bar{V}_{j}$ represents the weighting factor of $j$ number of quality characteristics of the jth principal component. For example, if $Q_{j}$ represents the $j$ th quality characteristic, the $j$ th principal component $\psi_{j}$ can be treated as a quality indicator with the required quality characteristic.

$$
\psi_{j}=V_{1 j} Q_{1}+V_{2 j} Q_{2}+\ldots \ldots \ldots \ldots \ldots \ldots \ldots+V_{j j} Q_{j}=\bar{V}_{j}^{\prime} \bar{Q}
$$

It is to be noted that every principal component $\psi_{j}$ represents a certain degree of explanation of the variation of quality characteristics, namely the accountability proportion (AP). When several principal components are accumulated, it increases the accountability proportion of quality characteristics. This is denoted as cumulative accountability proportion (CAP). If a quality characteristic $Q_{j}$ strongly dominates in the $j t h$ principal component, this principal component becomes the major indicator of such a quality characteristic. It should be noted that one quality indicator may often represent all the multi-quality characteristics. Selection of individual principal components $\left(\psi_{j}\right)$, those to be included in the composite quality indicator $\psi$, depends on their individual accountability proportion.

\section{Taguchi method}

Taguchi's philosophy, developed by Dr. Genichi Taguchi, is an efficient tool for the design of high quality manufacturing system. Taguchi's Orthogonal Array (OA) provides a set of well-balanced experiments (with less number of experimental runs), and Taguchi's signal-to-noise ratios $(\mathrm{S} / \mathrm{N})$, which are logarithmic functions of desired output; serve as objective functions in the optimization process. Taguchi method uses a statistical measure of performance called signal-to-noise ratio. The $\mathrm{S} / \mathrm{N}$ ratio takes both the mean and the variability into account. The $\mathrm{S} / \mathrm{N}$ ratio is the ratio of the mean (Signal) to the standard deviation (Noise). The ratio depends on the quality characteristics of the product/process to be optimized. The standard $\mathrm{S} / \mathrm{N}$ ratios generally used are as follows: - Nominal-is-Best (NB), lower-the-better (LB) and Higher-the-Better (HB). The optimal setting is the parameter combination, which has the highest S/N ratio, (Taguchi, 1986; Mahapatra and Chaturvedi, 2009). Because, irrespective of the quality criteria may be $(\mathrm{NB}, \mathrm{LB}, \mathrm{HB}) \mathrm{S} / \mathrm{N}$ ratio should always be maximized. Once experimental data (quality attribute value) is normalized using NB/LB/HB criteria; normalized value lies in between zero to one. Zero represents worst quality to be rejected and one represents most satisfactory quality. Since $\mathrm{S} / \mathrm{N}$ ratio is expressed as mean (signal) to the noise (deviation from the target); maximizing $\mathrm{S} / \mathrm{N}$ ratio ensures minimum deviation and hence it is $(\mathrm{S} / \mathrm{N}$ ratio) to be maximized.

Taguchi's S/N Ratio for (NB) Nominal-the-best

(Quality characteristics is usually a nominal output, say Diameter)

$\eta=10 \ln _{10} \frac{1}{n} \sum_{i=1}^{n} \frac{\mu^{2}}{\sigma^{2}}$

\section{Taguchi's S/N Ratio for (LB) Lower-the-better}

(Quality characteristics is usually a nominal output, say Defects) 


$$
\eta=-10 \ln _{10} \frac{1}{n} \sum_{i=1}^{n} y_{i}^{2}
$$

\section{Taguchi's S/N Ratio for (HB) Higher-the-better}

(Quality characteristics is usually a nominal output, say Current)

$$
\begin{aligned}
& \eta=-10 \ln _{10} \frac{1}{n} \sum_{i=1}^{n} \frac{1}{y_{i}^{2}} \\
& \eta=S / N \text { Ratio, } y_{i}=\text { Value of the quality characteristic at ith setting }, \\
& n=\text { Total number of trialruns at ith setting }, \mu=\text { Mean }, \sigma=S \text { tan dard Deviation }
\end{aligned}
$$

\section{Experimental setup and procedure}

Details of experimental plan are given below.

a) Checking and preparing the Vertical CNC milling machine system ready for performing the machining operation.

b) Preparing rectangular aluminum plates of size $95 \mathrm{~mm} \times 75 \mathrm{~mm} \times 10 \mathrm{~mm}$ in shaping machine for performing CNC end milling.

c) Calculating weight of each plate by the high precision digital balance meter before machining.

d) Creating CNC part programs for tool paths with specific commands using different levels of spindle speed, feed and depth of cut and then performing end milling operation.

e) Calculating weight of each machined plate again by the digital balance meter.

f) Measuring surface roughness and surface profile with the help of a portable stylus-type profilometer, Talysurf (Taylor Hobson, Surtronic 3+, UK)

The present experimental work seeks to evaluate the optimal result for selection of spindle speed (S), feed rate $(f)$ and depth of cut $(d)$ in order to achieve good surface roughness $\left(\mathrm{R}_{\mathrm{a}}\right.$ value) and high material removal rate (MRR) during the CNC end milling process. Table 1 represents selected process control parameters used during the experiments. These parameters have been allowed to vary in three different levels.

Table 1: Process control parameters and their limits

\begin{tabular}{cccc}
\hline Coded levels & $\begin{array}{c}\text { Spindle speed, S } \\
(\mathrm{rpm})\end{array}$ & $\begin{array}{c}\text { Feed rate, } f \\
(\mathrm{~mm} / \mathrm{min})\end{array}$ & $\begin{array}{c}\text { Depth of cut, } d \\
(\mathrm{~mm})\end{array}$ \\
\hline-1 & 300 & 30 & 0.2 \\
0 & 450 & 50 & 0.5 \\
+1 & 600 & 70 & 0.8 \\
\hline
\end{tabular}

The values of coded and actual value of each parameter used in this work are listed in Table 1. The experimental matrix adopted as per Taguchi's $\mathrm{L}_{9}$ Orthogonal Array (OA) design. Based on the scope on parameter variation available in the machine/setup; the parameter's range of variation has been selected. The machine used for the milling is a 'DYNA V4.5' CNC vertical milling machine having the control system SINUMERIK $802 \mathrm{D}$ with a vertical milling head. For generating the milled surfaces, CNC part programs for tool paths have been created with specific commands. The photograph of DYNA V4.5 CNC milling machine has been shown in Figure 1. The compressed coolant servo-cut has been used as cutting environment.

Commercially available CVD coated carbide tools have been used. The tools used are flat end mill cutters produced by WIDIA (EM-TiAlN). The tools are coated with TiAlN coating. For each material a new cutter of same specification has been used. The details of the end milling cutter are given below:

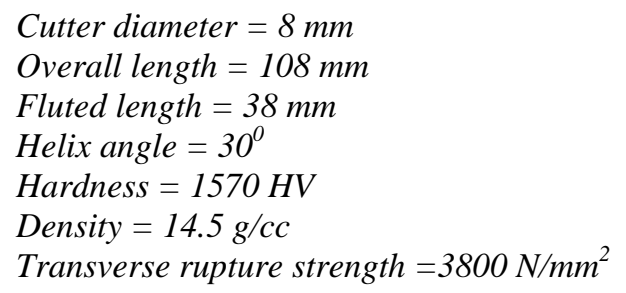


The test work pieces are made of Aluminum of size $95 \mathrm{~mm}$ x $75 \mathrm{~mm}$ x 10mm rectangular plate. Different plates of same dimension and material are used for each experimental run. Material properties are given below:

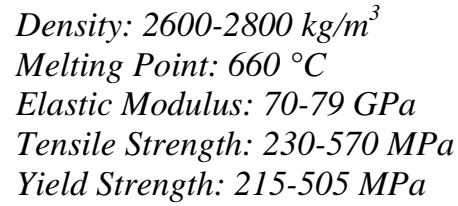

Roughness measurement has been done using a portable stylus-type profilometer, Talysurf (Taylor Hobson, Surtronic 3+, UK).

Material removal rate (MRR) has been calculated from the difference of weight of work piece before and after experiment.

$$
M R R=\frac{W_{i}-W_{f}}{\rho_{s} t} m m^{3} \cdot \mathrm{min}^{-1}
$$

Here, $\mathrm{W}_{\mathrm{i}}$ is the initial weight of work piece in $\mathrm{g} ; W_{f}$ is the final weight of work piece in $\mathrm{g}$; $\mathrm{t}$ is the machining time in minutes; $\rho_{\mathrm{s}}$ is the density of aluminum $\left(2.7 \times 10^{-3} \mathrm{~g} / \mathrm{mm}^{3}\right)$.

The weight of the work piece has been measured in a high precision digital balance meter (Model: DHD - 200 Macro single pan DIGITAL reading electrically operated analytical balance made by Dhona Instruments), which can measure up to the accuracy of $10^{-4} \mathrm{~g}$ and thus eliminates the possibility of large error while calculating material removal rate (MRR) in CNC end milling process. Experimental data of $\mathrm{R}_{\mathrm{a}}$ value and MRR (material removal rate) corresponding to $\mathrm{L}_{9} \mathrm{OA}$ design of experiment has been tabulated below (Table 2).

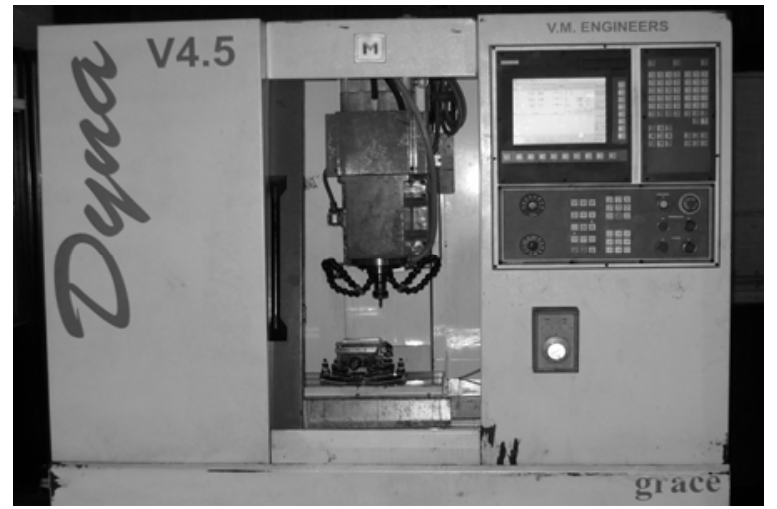

Figure 1: CNC vertical milling machine used for experiment

Table 2: Experimental design and collected response data

\begin{tabular}{cccccc}
\hline \multirow{2}{*}{ S1. No. } & \multicolumn{2}{c}{ Parametric combination (Design of experiment) } & \multicolumn{2}{c}{ Response features } \\
\cline { 2 - 6 } & $\begin{array}{c}\text { Spindle Speed } \\
(\mathrm{rpm})\end{array}$ & $\begin{array}{c}\text { Feed rate } \\
(\mathrm{mm} / \mathrm{min})\end{array}$ & $\begin{array}{c}\text { Depth of Cut } \\
(\mathrm{mm})\end{array}$ & $\begin{array}{c}\mathrm{R}_{\mathrm{a}} \\
(\mu \mathrm{m})\end{array}$ & $\begin{array}{c}\mathrm{MRR} \\
\left(\mathrm{mm}^{3} / \mathrm{min}\right)\end{array}$ \\
\hline 1 & 300 & 30 & 0.2 & 1.1670 & 62.500 \\
2 & 300 & 50 & 0.5 & 1.5440 & 229.743 \\
3 & 300 & 70 & 0.8 & 1.7200 & 428.803 \\
4 & 450 & 30 & 0.5 & 0.9696 & 133.076 \\
5 & 450 & 50 & 0.8 & 1.5410 & 304.770 \\
6 & 450 & 70 & 0.2 & 1.2100 & 148.200 \\
7 & 600 & 30 & 0.8 & 1.2500 & 172.811 \\
8 & 600 & 50 & 0.2 & 1.0000 & 116.400 \\
9 & 600 & 70 & 0.5 & 1.440 & 338.680 \\
\hline
\end{tabular}




\section{Methodology adopted for optimization (Datta et al., 2009b)}

Assuming, the number of experimental runs in Taguchi's OA design is $m$, and the number of quality characteristics is $n$. The experimental results can be expressed by the following series: $X_{1}, X_{2}, X_{3}, \ldots \ldots \ldots, X_{i}, \ldots ., X_{m}$

Here,

$$
\begin{aligned}
& X_{1}=\left\{X_{1}(1), X_{1}(2) \ldots \ldots \ldots X_{1}(k) \ldots . . X_{1}(n)\right\} \\
& \cdot \\
& \cdot \\
& \cdot \\
& X_{i}=\left\{X_{i}(1), X_{i}(2) \ldots \ldots \ldots X_{i}(k) \ldots . . X_{i}(n)\right\} \\
& \cdot \\
& \cdot \\
& \cdot \\
& X_{m}=\left\{X_{m}(1), X_{m}(2) \ldots \ldots \ldots X_{m}(k) \ldots . . X_{m}(n)\right\}
\end{aligned}
$$$$
\text { (1) }
$$

Here, $X_{i}$ represents the $i$ th experimental results and is called the comparative sequence in grey relational analysis.

Let, $X_{0}$ be the reference sequence:

$$
\text { Let, } X_{0}=\left\{X_{0}(1), X_{0}(2) \ldots \ldots . . . X_{0}(k) \ldots . . X_{0}(n)\right\}
$$

The value of the elements in the reference sequence means the optimal value of the corresponding quality characteristic. $X_{0}$ and $X_{i}$ both includes $n$ elements, and $X_{0}(k)$ and $X_{i}(k)$ represent the numeric value of $k$ th element in the reference sequence and the comparative sequence, respectively, $k=1,2, \ldots \ldots ., n$. The following illustrates the proposed parameter optimization procedures in detail, (Su and Tong, 1997).

\section{Step 1: Normalization of the responses (quality characteristics)}

When the range of the series is too large or the optimal value of a quality characteristic is too enormous, it will cause the influence of some factors to be ignored. The original experimental data must be normalized to eliminate such effect. There are three different types of data normalization according to whether we require the LB (lower-the-better), the HB (higher-the-better) and NB (nominal-the-best). The normalization is taken by the following equations.

(a) LB (lower-the-better)

$$
X_{i}^{*}(k)=\frac{\min X_{i}(k)}{X_{i}(k)}
$$

(b) HB (higher-the-better)

$$
X_{i}^{*}(k)=\frac{X_{i}(k)}{\max X_{i}(k)}
$$

(c) NB (nominal-the-best)

$$
X_{i}^{*}(k)=\frac{\min \left\{X_{i}(k), X_{0 b}(k)\right\}}{\max \left\{X_{i}(k), X_{0 b}(k)\right\}}
$$


Here, $\begin{aligned} & i=1,2, \ldots \ldots . ., m \\ & k=1,2, \ldots \ldots \ldots, n\end{aligned}$

$X_{i}^{*}(k)$ is the normalized data of the $k$ th element in the $i$ th sequence.

$X_{0 b}(k)$ is the desired value of the $k$ th quality characteristic. After data normalization, the value of $X_{i}^{*}(k)$ will be between 0 and 1 . The series $X_{i}^{*}, i=1,2,3, \ldots \ldots . ., m$. can be viewed as the comparative sequence used in the grey relational analysis.

\section{Step 2: Checking for correlation between two quality characteristics}

$$
Q_{i}=\left\{X_{0}^{*}(i), X_{1}^{*}(i), X_{2}^{*}(i), \ldots \ldots \ldots \ldots, X_{m}^{*}(i)\right\}
$$

Let,

$$
\text { where, } i=1,2, \ldots \ldots, n \text {. }
$$

It is the normalized series of the $i$ th quality characteristic. The correlation coefficient between two quality characteristics is calculated by the following equation:

$$
\begin{gathered}
\rho_{j k}=\frac{\operatorname{Cov}\left(Q_{j}, Q_{k}\right)}{\sigma_{Q_{j}} \times \sigma_{Q_{k}}}, \\
j=1,2,3 \ldots \ldots, n . \\
\text { here, } \begin{array}{c}
k=1,2,3, \ldots \ldots ., n ., \\
j \neq k
\end{array}
\end{gathered}
$$

Here, $\rho_{j k}$ is the correlation coefficient between quality characteristic $j$ and quality characteristic $k ; \operatorname{Cov}\left(Q_{j}, Q_{k}\right)$ is the covariance of quality characteristic $j$ and quality characteristic $k ; \sigma_{Q_{j}}$ and $\sigma_{Q_{k}}$ are the standard deviation of quality characteristic $j$ and quality characteristic $k$, respectively.

The correlation is checked by testing the following hypothesis:

$$
\left\{\begin{array}{lr}
H_{0}: \rho_{j k}=0 & \text { (There is nocorrelation) } \\
H_{1}: \rho_{j k} \neq 0 & \text { (There is correlation) }
\end{array}\right.
$$

\section{Step 3: Calculation of the principal component score}

(a) Calculate the Eigenvalue $\lambda_{k}$ and the corresponding eigenvector $\beta_{k}(k=1,2, \ldots \ldots, n)$ from the correlation matrix formed by all quality characteristics.

(b) Calculate the principal component scores of the normalized reference sequence and comparative sequences using the equation shown below:

$Y_{i}(k)=\sum_{j=1}^{n} X_{i}^{*}(j) \beta_{k j}, \quad i=0,1,2, \ldots \ldots ., m ; k=1,2, \ldots \ldots ., n$.

where, $Y_{i}(k)$ is the principal component score of the $k$ th element in the $i$ th series.

$X_{i}^{*}(j)$ is the normalized value of the $j$ th element in the $i$ th sequence, and $\beta_{k j}$ is the $j$ th element of eigenvector $\beta_{k}$. 
(c) The principal component having highest accountability proportion (AP) can be treated as the overall quality index; which is to be optimized finally. The quality loss $\Delta_{0, i}(k)$ of that index (compared to ideal situation) is calculated as follow:

(d)

$$
\Delta_{0, i}(k)=\left\{\begin{array}{l}
\left|X_{0}^{*}(k)-X_{i}^{*}(k)\right|, \text { no significant correlation between quality characteristics } \\
\left|Y_{0}(k)-Y_{i}(k)\right|, \quad \text { Significant correlation between quality characteristics }
\end{array}\right.
$$

Optimal setting is then evaluated by minimizing this $\Delta_{0, i}(k)$ (quality loss estimate) by using Taguchi method.

\section{Data analysis and evaluation of optimal setting}

Experimental data (Table 2) have been normalized using equation (8). For surface roughness and MRR, a (Higher-the-better) HB criterion has been selected. The normalized data are shown in Table 3.

Table 3: Data preprocessing of each performance characteristics (Normalization of experimental data)

\begin{tabular}{ccc}
\hline \multirow{2}{*}{ Sl. No. } & \multicolumn{2}{c}{ Normalized data } \\
\cline { 2 - 3 } Ideal condition & Surface roughness & MRR \\
1 & 1.0000 & 1.0000 \\
2 & 0.6785 & 0.1458 \\
3 & 0.8977 & 0.5358 \\
4 & 1.0000 & 1.0000 \\
5 & 0.5637 & 0.3103 \\
6 & 0.8959 & 0.7107 \\
7 & 0.7035 & 0.3456 \\
8 & 0.7267 & 0.4030 \\
9 & 0.5814 & 0.2715 \\
\end{tabular}

After normalization, a check has been made to verify whether the responses i.e. quality indices are correlated or not. The correlation coefficient between surface roughness and MRR becomes 0.901 ( $p$-value $=0.000$ ), which indicates that responses are highly correlated. The coefficient of correlation, between two responses, has been calculated using equation (10).

Table 4: (Analysis of correlation matrix)

Eigenvalues, eigenvectors, accountability proportion (AP) and cumulative accountability proportion (CAP) computed for the four major quality indicators

\begin{tabular}{lcc}
\hline & $\psi_{1}$ & $\psi_{2}$ \\
\hline Eigenvalue & 1.9014 & 0.0986 \\
Eigenvector & {$\left[\begin{array}{c}0.707 \\
0.707\end{array}\right]$} & {$\left[\begin{array}{c}0.707 \\
-0.707\end{array}\right]$} \\
AP (Accountability proportion) & 0.951 & 0.049 \\
CAP(Cumulative accountability proportion) & 0.951 & 1.000 \\
\hline
\end{tabular}

In order to eliminate response correlations, Principal Component Analysis (PCA) has been applied to derive two independent quality indexes (called principal components), using equation (11). The analysis of correlation matrix is shown in Table 4 . The independent quality indexes are denoted as principal components $\psi_{1}\left(1^{\text {st }} \mathrm{PC}\right)$ and $\psi_{2}\left(2^{\text {nd }} \mathrm{PC}\right)$. Table 5 represents the values of these independent principal components for 9 experimental runs.

It has been found that $1^{\text {st }}$ Principal Component itself can describe $95.1 \%$ variability in the data $(\mathrm{AP}=0.951)$. Therefore, the $2^{\text {nd }} \mathrm{PC}$ i.e. $\psi_{2}$ can be eliminated and the $1^{\text {st }} \mathrm{PC}$ i.e. $\psi_{1}$ has been treated as the equivalent quality index. Quality loss estimates have been calculated and values are tabulated in Table 6. 
Table 5: Principal components in all $\mathrm{L}_{9} \mathrm{OA}$ experimental observations

\begin{tabular}{ccc}
\hline & \multicolumn{2}{c}{$\begin{array}{c}\text { Uncorrelated quality attributes } \\
\text { (Principal components) }\end{array}$} \\
\cline { 2 - 3 } S1. No. & $\left(1^{\text {st }} \mathrm{PC}\right) \psi_{1}$ & $\left(2^{\text {nd }} \mathrm{PC}\right) \psi_{2}$ \\
\hline Ideal condition & 1.4140 & 0.0000 \\
1 & 0.5828 & 0.3766 \\
2 & 1.0135 & 0.2559 \\
3 & 1.4140 & 0.0000 \\
4 & 0.6179 & 0.1792 \\
5 & 1.1359 & 0.1309 \\
6 & 0.7417 & 0.2530 \\
7 & 0.7987 & 0.2289 \\
8 & 0.6030 & 0.2191 \\
9 & 1.1503 & 0.0335 \\
\hline
\end{tabular}

Table 6: Calculation of $\Delta_{0 i}(k)$ (quality loss) for $1^{\text {st }}$ principal components

\begin{tabular}{rlc}
\hline Sl. No. & $\Delta_{0 i}(1 s t P C)$ & S/N ratio \\
\hline 1 & 0.8312 & 1.6059 \\
2 & 0.4005 & 7.9479 \\
3 & $0.0000 \sim$ assumed as 0.00005 & 86.0206 \\
4 & 0.7961 & 1.9806 \\
5 & 0.2781 & 11.1160 \\
6 & 0.6723 & 3.4487 \\
7 & 0.6153 & 4.2183 \\
8 & 0.8110 & 1.8196 \\
9 & 0.2637 & 11.5778 \\
\hline
\end{tabular}

Taguchi's Lower-the-Better (LB) criterion has been used to minimize this quality loss. Figure 2 reveals S/N ratio plot from which optimal factorial combination has been evaluated. The optimal setting becomes S1 f3 d3. Result has been verified through confirmatory test, showed satisfactory results (improvement in quality).

The maximum possible number of the principal components to be computed is equal to the number of responses. The present study deals with two responses and hence two principal components $\psi_{1}$ and $\psi_{2}$. Accountability proportion of $\psi_{2}$ being negligible compared to $\psi_{1} ; \psi_{2}$ has been neglected and $\psi_{1}$ has been treated as the major principal component (composite principal component). But the case where to deal with more than two principal components in which accountability proportion of all principal component bear remarkable values those cannot be neglected; the problem of computing composite principal component arises (Datta et al., 2009a).

The optimization technique adapted in the present work takes care of response correlations which are being neglected by traditional optimization techniques; the method is also not free from limitations. The main disadvantage of this method is the lack of physical interpretation of individual principal components. While eliminating response correlation; correlated responses are converted into independent i.e. uncorrelated quality indices (principal components) which do exist in practice. It is just a mathematical index to succeed in case of a correlated multi-response optimization problem. There are various formulas on aggregation of individual principal components as reported in literature to compute a (MPI) multi-response performance index (composite principal component). There is no strong mathematical background to compute this MPI. Therefore, it depends on the discretion of decision makers [Datta et al. (2009a)]. To avoid this discrepancy the study explores a meaningful ideology on elimination of individual principal components having negligible accountability proportion and to consider the principal component (having highest accountability proportion) as the representative overall performance index. 


\section{$\mathrm{S} / \mathrm{N}$ ratio of quality loss (of 1 st $\mathrm{PC}$ )}

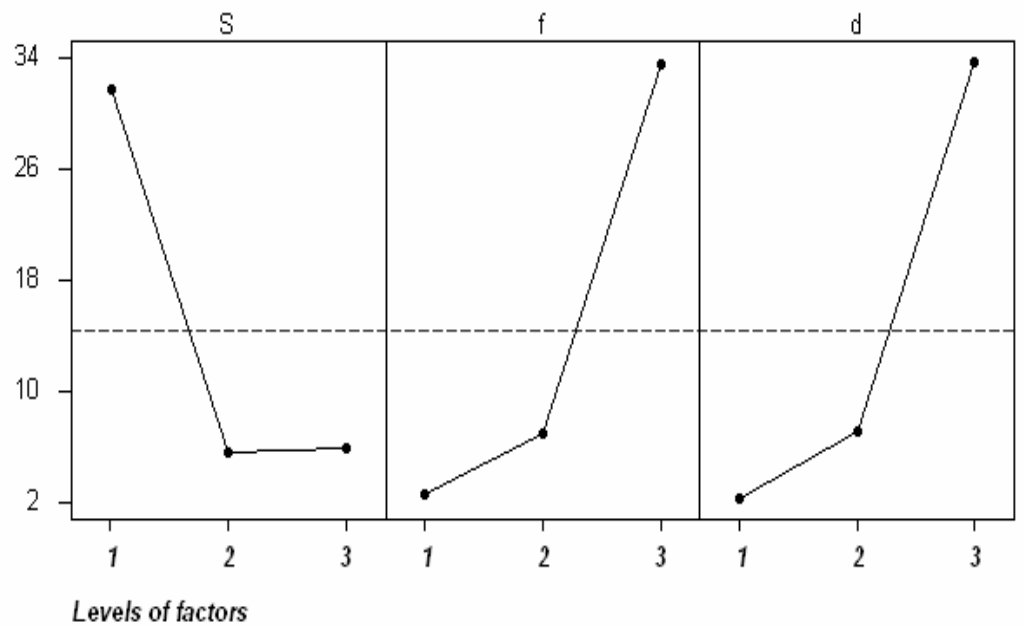

Figure 2: S/N ratio plot (Evaluation of optimal setting)

\section{Conclusions}

In the foregoing study, the use of PCA based hybrid Taguchi method has been proposed and adopted for solution of multiobjective optimization, along with a case study, in CNC end milling operation. From the study and analyses, the following conclusions can be drawn.

* The proposed method has been found efficient for solving multi-attribute decision making problem i.e., for multiobjective product as well as process optimization; for continuous quality improvement.

* Application of PCA can eliminate multi co-linearity (correlation) of the output responses and transform these correlated responses into uncorrelated quality indices called principal components. Absence of correlation between the responses is the basic assumption for applying Taguchi optimization technique.

* It can be recommended that the PCA based hybrid Taguchi method is good, for example, in case of processes (chemical and pharmaceutical) industries when there are hundreds of response variables.

In the foregoing study, interaction effects of process control parameters have been neglected. But in practical case, this assumption may not be valid. Therefore, there exists scope to incorporate these interactions in the analyses of optimization. If interactive effects of factors are considered, it would be very interesting to find how Taguchi design of experiment changes from the previous case. The application feasibility of the said technique can be investigated in problems dealing with ample process responses.

\section{References}

Datta S., Nandi G., Bandyopadhyay A. and Pal P.K., 2009a. Application of PCA based hybrid Taguchi method for multi-criteria optimization of submerged arc weld: A case study, International Journal of Advanced Manufacturing Technology, Vol. 45, No. 3-4, pp. 276-286.

Datta S., Nandi G. and Bandyopadhyay A, 2009b. Application of entropy measurement technique in grey based Taguchi method for solution of correlated multiple response optimization problems: A case study in welding, Journal of Manufacturing Systems, (in press) DOI: 10.1016/j.jmsy.2009.08.001.

Ghani J.A., Choudhury I.A. and Hassan H.H., 2004. Application of Taguchi method in the optimization of end milling parameters, Journal of Material Processing Technology, Vol. 145, No. 1, pp. 84-92.

Johnson R.A. and Wichern D.W. 2002, Applied Multivariate Statistical Analysis, Prentice-Hall, Inc., Englewood Cliffs, New Jersey 07632.

Kopac J. and Krajnik P., 2007. Robust design of flank milling parameters based on grey-Taguchi method, Journal of Material Processing Technology, Vol. 191, No. 1-3, pp. 400-403.

Mahapatra S.S. and Chaturvedi, V., 2009, Modeling and analysis of abrasive wear performance of composites using Taguchi approach, International Journal of Engineering, Science and Technology, Vol. 1, No. 1, pp. 123-135.

Oktem H., Erzurumlu T. and Kurtaran H., 2005. Application of response surface methodology in the optimization of cutting conditions for surface roughness, Journal of Material Processing Technology, Vol. 170, No. 1-2, pp. 11-16. 
Su C.T. and Tong L.I., 1997. Multi-response robust design by principal component analysis, Total Quality Management, Vol. 8, No. 6, pp. 409-416.

Taguchi G., 1986. Introduction to quality engineering, Proceedings of Asian Productivity Organization, UNIPUB, White Plains, NY.

Yang L.J. and Chen C.J., 2001. A systematic approach for identifying optimum surface roughness performance in end-milling operations, Journal of Industrial Technology, Vol 17, pp.1-8.

\section{Biographical notes}

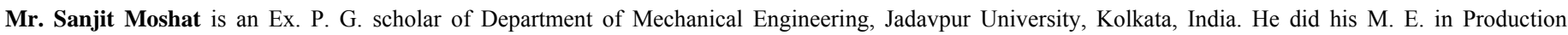
Engineering from Jadavpur University in the year 2007.

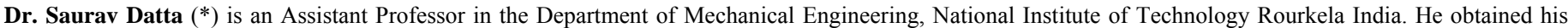

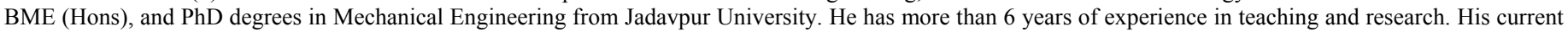

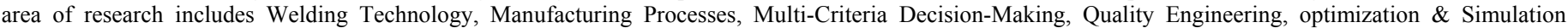
modeling.

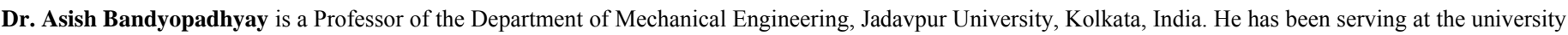

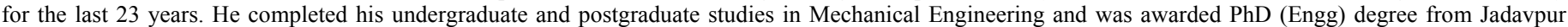

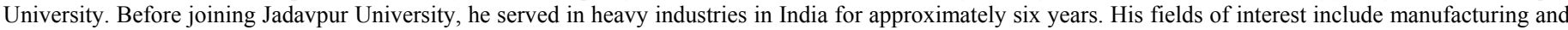
machining technology and heat transfer.

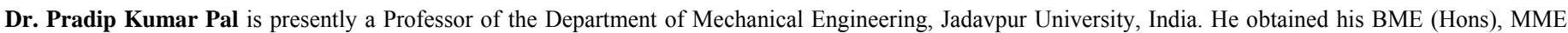

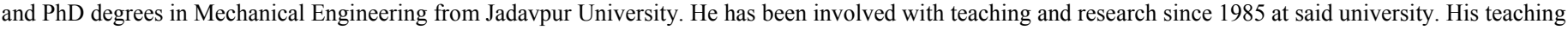
and research areas include manufacturing science, machine tool vibration and welding technology.

Received December 2009

Accepted January 2010

Final acceptance in revised form February 2010 